\title{
Reforming Innercity Bus Transportation in a Developing Country: A Passenger-Driven Model
}

\author{
Syed Saad Andaleeb, The Pennsylvania State University at Erie \\ Mahmudul Haq, BRAC University, Bangladesh \\ Rubina I. Ahmed, East West University, Bangladesh
}

\begin{abstract}
The transportation system in Dhaka City, Bangladesh, requires significant improvements. The shortage of motorized vehicles and the excessive number of nonmotorized vehicles on the city's streets have been the cause of unbearable traffic congestion, leading to negative externalities such as productivity loss, increase in stress levels, and adverse health effects from pollution. In a city inhabited by more than 12 million people, predominantly representing the middle-and lower-middle class, a well-organized low-cost bus transportation system is yet to emerge to resolve the city's transportation problems. This study explores ways of improving bus transportation services in Dhaka. Eight factors were identified to address satisfaction levels of regular bus users whose opinions and concerns are deemed vital in making bus services in the city better organized, need based, and service oriented. Using factor analysis and multiple regression, five of the eight selected factors were found to have significant effects on passenger satisfaction. These include comfort levels, staff behavior, number of buses changed to reach destination, supervision, and waiting facilities. Policy implications are discussed in view of the findings.
\end{abstract}




\section{Introduction}

The transportation needs of major cities will present significant challenges for policy makers as the unpredictable shifts in population dynamics in response to need for employment, housing, and sustenance continues. For example, bustling cities in India, China, Mexico, and Thailand today are struggling to keep pace with the demand for more and better transportation as the number of people in these cities begins to swell with economic growth and development. With a rise in demand for transportation comes congestion and other problems. Delays, uncertainty, and stress levels are also beginning to take their toll on both individuals and society (Morris et al. 2005). Improving public transportation is seen by many as critical (Ison and Wall 2002). The UK has already begun to look 10 years ahead to shape its transportation policy (Department of Environment, Transport and the Regions 2000). In South Korea also, the Seoul Metropolitan Government has "completely reorganized bus services, installed (rapid transit) corridors, improved coordination of metro and bus services, and fully integrated the fare structure and ticketing systems between routes, as well as modes" (Pucher et al. 2005).

The transportation system in Dhaka City, Bangladesh, catering to more than 12 million people, faces numerous and significant challenges. The complex and heterogeneous traffic pool, largely dominated by nonmotorized vehicles (especially rickshaws), poorly maintained motorized vehicles, and the lack of enforcement of traffic rules, creates serious and often unbearable congestion and heavy pollution in the city's streets. These factors also contribute enormously to the travel-related suffering of city dwellers, a situation that by many accounts is deteriorating rapidly.

Unfortunately, research on Dhaka City's transportation problems is seriously lacking. According to Mannan and Karim (2001), the number of vehicles per 100,000 people in the city is only 2,630; of these, 2,195 are nonmotorized. More significantly, rickshaws (a traditional, human-powered vehicle) and other nonmotorized vehicles account for 50 percent of the traffic flows. About 60 percent of the people travel on foot while almost half of the remaining people use nonmotorized vehicles. Moreover, roughly 40 percent of passenger trips and 5 percent of the freight movements are by rickshaws, estimated to be about 150,000 in number (Mannan and Karim 2001) and registered with Dhaka City Corporation. If we consider the number of unregistered rickshaws, the total estimate is much higher and may well be above 450,000. Rickshaws are used for lack of better alternatives. Unfortunately, these slow-moving vehicles are among the main causes of severe 
traffic congestion, particularly in the city's intersections, contributing to loss of work hours, exposure to health hazards from vehicular emissions, uncertainty of being on time, being subjected to adverse weather conditions, and many other inconveniences.

An inadequate road network is yet another impediment to the smooth flow of traffic in Dhaka City. Ideally, the road transportation network should cover about 25 percent of a city's surface area (Banglapedia). There are approximately 436 kilometers of four-lane roads and 1,408 kilometers of two-lane roads covering about 8 percent of Dhaka City's surface area. Most of these roads are poorly maintained. Almost two thirds of the available roads do not have engineered surfaces, and although more than a quarter of the roads have surface dressing, these show signs of extensive deterioration (Mannan and Karim 2001). Also, while more than half the city's travelers are pedestrians, a meager 220 kilometers of sidewalks exist (Banglapedia). Many sidewalks are occupied by street vendors that constrict space available to pedestrians who then spill over onto the streets to narrow traffic lanes and further aggravate the congestion.

Other problems in the city's traffic system include lack of clear traffic regulations and their poor enforcement and environment pollution from old and ill-maintained motorized vehicles that emanate toxic suspended particulate matters (SPM), carbon monoxide (CO), sulphur dioxide $\left(\mathrm{SO}_{2}\right)$, and airborne lead (Asian Development Bank 2001).

Bringing about long-term improvements in the city's worsening traffic system requires a change in the status quo and large investments in the transportation and road-communication sector. The World Bank is currently financing the government of Bangladesh to implement the Dhaka Urban Transport Project, a public transport system in Dhaka City estimated to cost Tk.10,000 million (World Bank 1999). According to the World Bank, Dhaka's transport problems are multifaceted and massive, and require a program phased in over several years.

The overall grim picture of the city's transportation problems and constraints suggests the need to bring about significant improvements. Although suggestions have been made for exploration of underground and air space in various forums (subways and monorails), and these alternatives certainly have some attractive features for relieving congestion, it is difficult to envision their immediate implementation in view of their technical and financial feasibilities. 
What is imminent, however, is to improve the ground transportation system in the city, which today is comprised of rickshaws, buses, minibuses, premium (air-conditioned) buses, taxis, CNG auto rickshaws, and some commuter train facilities. Rickshaws, powered by raw muscle, are slow, lack capacity, and cause congestion. Considering the size of the taxis and auto rickshaws vis-à-vis their passenger-carrying capacity, their expansion also does not appear to be a suitable solution to the congestion problem. Commuter trains block traffic frequently at crossings and exacerbate the congestion. Under the circumstances and because of the dominance of a low-income population in the city, we advocate quick and significant capacity increases in the city's bus transportation network. While developed cities like London and Seoul have already begun to increase their investments in this mode, this option has not been satisfactorily explored or addressed for Dhaka City. A World Bank press release on the Dhaka Urban Transportation Project stated that Dhaka was perhaps the only city of its size without a well-organized bus system or mass transportation system (World Bank 1999).

The estimated number of registered buses and minibuses plying in the metropolis as of January 2003 was 4,500 (Ghani 2003), which is quite insufficient for this densely populated city. Significantly, this population is expected to double by 2025 (Ali 2004). Furthermore, a large majority of these buses are unfit both environmentally and mechanically, adversely affecting the city's ecological environment and being highly susceptible to accidents. Shortages of terminals and bus stops, the absence of separate lanes for buses, and the extreme lack of discipline in how and where buses stop on the thoroughfares create additional problems for traffic movement. Andaleeb (2003) depicts this as a failure of city management that contributes to the daily chaos.

An efficient and effective urban transportation system can promote urban development and renewal while providing adequate access and mobility. In fact, cities of developing countries are often the major engines for economic growth and improvements in city transportation can make them much more efficient and productive (Button 1993). The present deficiencies and inadequacies of the transportation sector in Bangladesh may be seen as one of the major impediments to the socioeconomic development of the country. In fact, Dhaka City has a major role to play in regional and subregional development (Karim 1998), which can be facilitated by an effective and efficient transportation system. Unfortunately, the poor transportation conditions in this bustling city curtail productivity and ultimately hinder international trade and economic development indirectly. For 
example, the links between the production centers and export shipment points are often decoupled by the horrible tangle of traffic. This reduces turnaround time, delays schedules, introduces related inefficiencies, dissatisfies overseas customers, and reduces competitiveness.

To induce more people to use the city's bus transportation system, it is important to obtain insights from actual users of the system about the changes they would like to see to better meet their needs. These insights must then be factored into a coherent strategy to provide real value to passengers. In this regard, Jen and $\mathrm{Hu}$ (2003) examine the perceived value model for Taiwan in which they contend that if benefits relative to costs of using bus service exceed the benefits and costs of alternative transportation modes, it will increase reuse intentions for buses. By identifying the key dimensions that offer value and influence customer satisfaction, alternative bus service strategies can be devised so that more people opt in favor of this service. In turn, this would alleviate the present congestion and related problems faced by the city and its population.

The two major research objectives of this study are to:

- Identify the key factors in the context of bus transportation in Dhaka City that explain customer/passenger satisfaction.

- Assess the relative importance of these dimensions to prioritize service provision and enhance passenger satisfaction.

\section{Literature Review}

Macario (2001) suggests that for any urban mobility system to provide appropriate and effective solutions to its clients, it must focus on the interaction between different agents of the system acting within and across different levels of planning and control (i.e., authorities, operators, suppliers of equipments, citizens, etc.). Macario also cites Ciuffini (1995) to emphasize the need for an adequate balance between the following dimensions:

- Transport dimension should obtain adequate balance between modes and means of transport, so that those who give up the use of private transportation have available good quality alternatives without any social, geographical or sectoral discrimination.

- Environmental dimension should establish a configuration of the urban 
mobility system that results in a total sum of pollution below the endurance level.

- Economic dimension should offer good "value for money," induce adaptive behavior from the users, and be able to create new financial resources to support investment.

- Social dimension should ensure that citizens are provided with an adequate mobility system to their needs and that no exclusion through price or any other criteria is imposed on the basis of economic or financial goals.

Macario also suggests that there is no perfect transportation system, and therefore the second best solution lies in establishing trade-offs between the various dimensions according to the socioeconomic and cultural reality of each specific environment (urban area). These trade-offs are conditioned by practical options that result from the interaction between the local, regional, and national levels of interventions. Clearly, an effective transportation system is a function of the strategic objectives designed to address stakeholders' interests.

Customer satisfaction with transportation services can be placed in the framework of stakeholder (passenger) interests. From this perspective, customer satisfaction with bus transportation can be used to find reasonable solutions to problems. There is, in fact, no comprehensive study on customer satisfaction with bus (or transportation) services in Bangladesh. Passengers' opinions regarding the quality of bus services can be vital in making this sector popular, attractive, and of greater value relative to other modes so as to induce more people to use it regularly.

In the absence of any comprehensive local research, we relied partially on studies conducted in other countries to identify the key attributes regarding urban bus transportation needs. However, the conditions existing in these countries relative to Bangladesh may raise questions of comparability. Acknowledging the differences, our findings are discussed below.

UK's Midlands operator Trent Buses conducted a thorough research with a view to improving services (Disney 1998) and identified customers' top requirements as: reliability/frequency of services, friendliness of services, clean bus interiors, comfort, value for money, clean bus exteriors, easy access, reasonable fares, and easy to understand and remember timetables. The top four items stood out in importance, and value for money was revealed as an embodiment of these attributes. Thus, if bus operators failed to deliver on the four items, they were not producing value for money. Low fare was not perceived as a critical requirement 
by a majority of the customers. Despite scoring high on reliability, Trent Buses fell short of expectations in the other three top values and was seen as weak in value for money. In the study, bus driver attitude and behavior were seen as problematic. Although only 10 percent of the drivers were responsible for this problem, what was far more damaging was the perception. Vehicle cleaning standards were also severely criticized.

In another study, analysis of complaints received by the Rail Users Consultative Committee (RUCC) in the UK revealed that staff attitude, reliability, punctuality, and cleanliness of the trains are sources of a majority of the complaints by passengers (Disney 1998). In India, transportation systems have also been criticized for their low quality of services reflected in the growing number of standing passengers, lack of punctuality, irregularity, and substandard amenities (Mishra and Nandagopal 1993).

Edvardsson (1998) examined written customer complaints to Goteborg Regional Public Transport AB in Sweden (GLAB), performed personal interviews with customers who had previously complained, and found staff attitude to be the dominant issue in the written complaints. In the personal interviews, however, punctuality emerged as the major problem. This indicates that customers accept lack of punctuality as an unfortunate but unavoidable effect of road congestion but it reduces their tolerance in other areas, particularly on how they are treated by front-line staff and on vehicle comfort levels embodied in heating and ventilation.

Based on the attributes identified in the above studies,in depth interviews with local passengers, as well as the authors' personal experiences with bus services, several hypotheses were initially developed for the Dhaka City research. This study is believed to be the first of its kind in Bangladesh that takes a broad and systematic customer-based approach to establishing the determinants of satisfaction with bus transportation services.

\section{Hypotheses}

Comfort is an important consideration for passengers using public transportation, which can be delivered by ensuring that the interior facilities (lights, fans, air-conditioners) function properly. Passengers also like to sit comfortably in good seats with enough legroom. In the event a passenger has to travel standing, he or she 
would like to have sufficient ceiling height to avoid crouching that can contribute to serious discomfort. It is posited therefore that:

\section{H1: The more comfortable the inside of the buses, the more satisfied the pas- sengers will be.}

Another factor deemed important in providing customer satisfaction was the quality of the ride. Often, in the in depth interviews, it was indicated that bus drivers blow the horn too often, drive too fast, overtake other vehicles dangerously, or brake hard frequently without any consideration to passengers' ability to maintain balance. In other words, passengers felt that the quality of the bus ride often poses serious hazards. We posit, therefore, that:

H2: The better the quality of the ride, the more satisfied the passengers will be.

Various categories of people use the city's bus transportation system. Many of them have little education and come from the lower income segment of society. Their social and economic context shapes their behaviors as passengers in ways that other societies may not fully comprehend. For example, issues regarding personal hygiene need to be addressed as some passengers may be traders who use the bus to go to the market with goods to trade; others may be grimy day laborers returning from work. In addition, passenger behaviors, such as pushing and shoving, in crammed buses often lead to altercations. These behaviors vary widely and may be perceived by others as inappropriate. We group these behaviors under whether passengers are disciplined, well-behaved, and clean, to posit that:

H3: The more passengers perceive the behaviors of copassengers as inappropriate, the less satisfied they will be with bus services.

Personal security has deteriorated alarmingly in Dhaka City in the past decade. Newspapers daily report stories of mugging, stealing, extortion, or even death as routine episodes. Cases of people losing their wallets to pickpockets are not uncommon, especially on public buses. These acts often instill a sense of insecurity among passengers that can attenuate their satisfaction with public transportation. We posit that:

H4: The greater the feelings of insecurity associated with the use of bus services, the lower the level of customer satisfaction with these services.

Passengers indicated during the in depth interviews that bus driver behaviors are often inappropriate. Overloading and crowding is a well-documented practice 
given the dearth of buses. Adding to this problem is the fact that buses stop almost anywhere to pick up or drop off passengers often in sheer haste. Rude and argumentative service personnel also mar the service experience. When such practices exist, we posit that:

H5: The greater the perception of improper behavior of the service personnel, the lower the satisfaction of the passengers.

There is also the perennial problem of capacity in the transportation sector, especially for bus services. It is reasonable to assume that people would prefer buses to rickshaws and baby taxis as a quick and more affordable alternative mode of transportation. Unfortunately, this preference often succumbs to the lack of availability of sufficient numbers of buses as reflected in the long waiting lines and the frantic dash to clamber aboard a bus upon its arrival at most stops. If a sufficient number of buses are made available for city commuters, enabling them to reach their destination comfortably and on time, it will allow more people to use buses for their daily traveling needs. This factor reflects the supply-side problem or inadequacy of the number of buses and lack of seating capacity to serve the needs of the public. We therefore posit that:

H6: The greater the perceived inadequacy of the capacity of bus services to serve passenger needs, the less satisfied the passengers.

Dhaka City commuters are not provided with good bus stand facilities. Very few permanent bus stands offer appropriate physical structures and facilities for people to board or disembark from the buses. Passengers often stand in queues by the roadside or on the road. Moreover, there is no shelter from the scorching sun or heavy rains. For a long wait at the bus stands, there is no alternative but to remain standing. In the evenings, not many stops are well lit and this can be a cause of consternation. Thus, it is proposed that:

H7: The better the waiting facilities at the bus stands, the more satisfied the passengers.

Bus routes are also seen by passengers as disorganized and not well coordinated. Many passengers have to change buses several times to reach their chosen destinations. Since, for the large majority, getting to the destinations quickly and efficiently is important, we posit that:

H8: The more frequently passengers have to change buses to get to their destinations, the less satisfied they will be with bus services. 
Many buses that ply the city have minimal inspection requirements and are quite dilapidated. They continue to operate on city streets for lack of systematic monitoring and supervision of their physical and mechanical conditions. With extensively damaged exteriors, nonfunctioning lights, broken windows, dented and bent bumpers, etc., they epitomize how many buses are able to avoid official inspection and maintenance while endangering public safety. This tangible, visible evidence of poor supervision by the authorities evokes feelings of uneasiness and may even attenuate confidence in bus services. For example, passengers may feel that the dilapidated conditions make the buses susceptible to accidents. They may even infer that flaws may exist in the buses' mechanical systems (engines, brakes, or clutches) for which passengers should have every reason to be apprehensive. It is important, therefore, that the government authorities responsible for supervising the physical and mechanical conditions of the buses, as well as the bus fares, do so regularly. Visible and vigorous supervision can raise the confidence of the passengers to use more public transportation. Hence we propose that:

H9: The greater the perceived government supervision of buses, the higher the level of passenger satisfaction.

\section{Research Method}

\section{Secondary Research}

Secondary research was first conducted to find studies on customer satisfaction with urban bus transportation services. Of the published studies that were found, most of them were from developed countries. These findings are likely to be different from the context of developing countries. However, the lack of indigenous literature led to our derivation of preliminary insights from the models found in developed countries.

\section{Questionnaire Design and Pretesting}

The questionnaire was based on secondary research, as well as in depth interviews and extensive brainstorming. The factors most apt to explain passenger satisfaction are reflected in the hypotheses. The survey questions measured each attribute of a factor on 7-point Likert scales with "strongly agree" reflecting the highest favorable response and "strongly disagree" indicating the least favorable response to each statement. Demographic questions were also included in the questionnaire and were mostly dichotomous and multichotomous in nature. The questionnaire was originally developed in English and translated and retranslated 
several times to obtain an appropriate local language (Bangla) version. The questionnaire was pretested on several randomly selected respondents. Minor adjustments were made to ensure conciseness, objectivity, and clarity. A panel of experts concurred on the content validity of the English and Bangla versions, confirming they were comparable.

\section{Sampling and Data Collection}

Dhaka City bus commuters were the target population because they were homogeneous in their use of buses but heterogeneous in other aspects (income, profession, etc.). Their opinions were mainly sought because they would be best able to evaluate existing levels of services and levels of satisfaction with such services. Probability sampling using a multistage cluster-sampling method was used to select a representative sample of commuters. The city was divided into several areas based on the location of the major bus stands/stops (e.g., Saidabad, Motijheel, Malibagh Crossing, Farm Gate, Gabtali, etc.). The entire area covered by each bus station was considered a cluster. From each cluster, a number of residential streets were randomly selected after an enumeration of the streets were completed. Systematic sampling was then used to select households. Respondents from each household were selected based on their usage of bus services. According to research protocol, respondents were asked not to identify themselves so that they could freely respond to the questions. They were also given the option to withdraw from the study or skip questions they did not want to answer.

Due to time and resource constraints, data were collected from 250 respondents via face to face interviews. In the event the respondents were educated, they were asked to self-administer the questionnaire; otherwise the interviewer filled the questionnaire based on the respondent's verbal responses.

\section{Analysis}

Frequency distributions were obtained to check for data entry errors and to obtain descriptive statistics. Data were then factor analyzed using principal components analysis with varimax rotation. Factor analysis is a data reduction technique that allows grouping of variables under a common theme or dimension (see Figure 1). A rotated structure of seven factors was expected based on the nine hypotheses since two of the hypotheses used single-item measures that were not included in the factor analysis. The seven factors were adequacy of buses, comfort, copassenger behavior, quality of the ride, insecurity perceptions, bus stand facilities, 


\section{Comfort}

1. Seats are comfortable.

2. Ceilings are at a comfortable height.

3. Facilities inside buses are in good condition.

4. There is enough foot space.

5. Buses are well maintained.

\section{Quality of the ride}

1. Drivers blow the horn too much.

2. Drivers drive too fast.

3. Buses overtake other vehicles dangerously.

4. Bus drivers frequently brake hard.

5. Buses often breakdown on the road.

\section{Copassenger behavior}

1. Passengers are disciplined.

2. Passengers are well behaved.

3. Passengers maintain cleanliness.

\section{Insecurity}

1. You are afraid of being robbed/mugged at the bus stand.

2. You are afraid of being pick-pocketed on the bus.

\section{Bus Operator/Conductor Behavior (single-item measure)}

1. Staff behave properly with you.

\section{Adequacy}

1. There is sufficient number of buses in the city.

2. Seats are generally available on the buses.

3. There are sufficient seats in the buses.

\section{Bus stand facilities}

1. There is enough lighting at the bus stands.

2. There is enough shelter at the bus stands against rain, sun, storm, etc.

3. There is enough seating arrangement at the bus stands.

\section{Change buses (single-item measure)}

1. You have to change buses many times to reach your destination.

\section{Government supervision}

1. Government supervision in checking bus fare is good.

2. Buses are randomly checked to ensure mechanical fitness and safety.

\section{Figure 1. Measures of Variables in the Model Using 7-point Likert Scales (anchored at strongly agree [7] and strongly disagree [1])}


and government supervision. The two single-item measures were about having to change several buses to get to the desired destination and behavior of the staff.

The initial factor structure did not support our selected dimensions. One factor, the adequacy of the buses, did not load as expected: the items were distributed over more than one factor. After systematic removal of these items, the final rotated solution with 21 items was retained. Six factors resulted from the final rotated solution; each was easy to interpret and explained 58 percent of the cumulative variation as shown in Table 1.

The six factors were comfort, quality of ride, copassenger behavior, insecurity, bus stand facilities, and perceived government supervision. Each factor was assessed for reliability using Cronbach's $\alpha$. The reliability coefficients of most of the factors, along with the measures of satisfaction, exceeded the value of 0.7 recommended by Nunnally (1978), except for bus stand facilities and supervision, which had coefficients of .57 and .43 , respectively. While these two values are on the low side, they were retained because of the preliminary and exploratory nature of this research. To assess the validity of the measures, the multiple items measuring each construct were further factor analyzed. In each case, the items always loaded on one factor only, lending support to their convergent validity. To these six factors were added the two additional single-item measures-behavior of the staff and need to change buses-that led to using eight variables in the final analyses. Thus, from the nine hypotheses proposed, we tested eight: inadequacy of bus capacity (H6) was dropped from the analysis as its measurement properties did not bear out as originally expected. This is not to imply that inadequacy of capacity as an issue is unimportant; perhaps it is reflected in the other constructs (comfort, need to change buses, etc.).

Descriptive statistics reflecting the mean scores, standard deviations, and reliability scores are provided in Table 2 . The results clearly indicate how users perceive bus services. Overall satisfaction (the dependent variable), measured on a 7-point scale, rated a mean score of $2.95(s=1.49)$. Comfort, comprising seven items, had a mean of $2.74(s=1.22)$; supervision had a mean of $2.65(s=1.60)$; bus stand facilities had a mean of $1.80(\mathrm{~s}=.98)$; ride quality measured in a negative sense had a mean of 4.96 ( $s=1.39)$; copassenger behavior had a mean of 3.91 ( $s=1.45)$; and insecurity had a mean of $5.39(s=1.60)$. Two single-item measures, staff behavior and need to change buses had mean scores of $3.38(s=1.86)$ and $3.93(s=2.30)$, respectively. Clearly, none of the variables purported to explain satisfaction with bus services are viewed favorably. The mean scores suggest the need for large-scale 


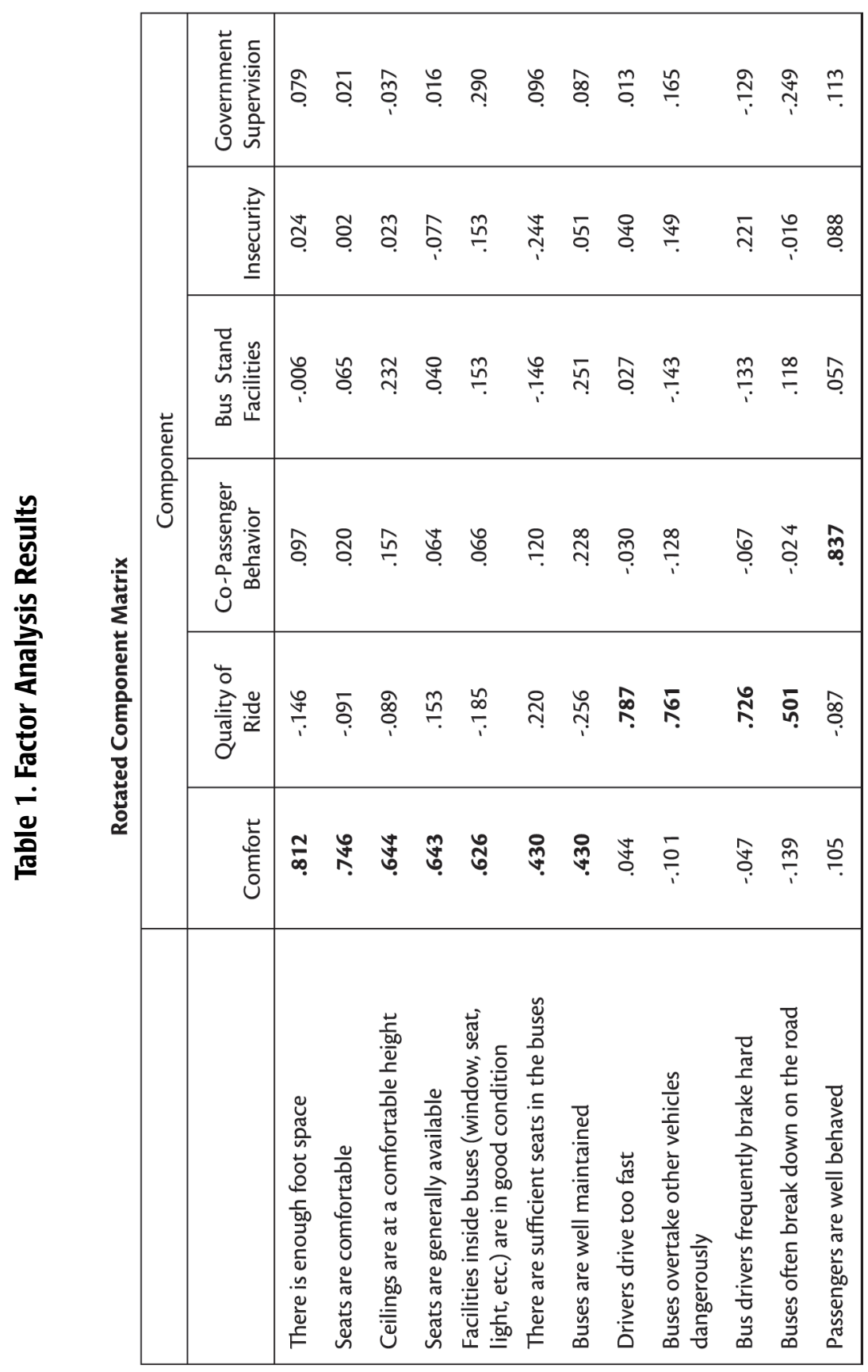




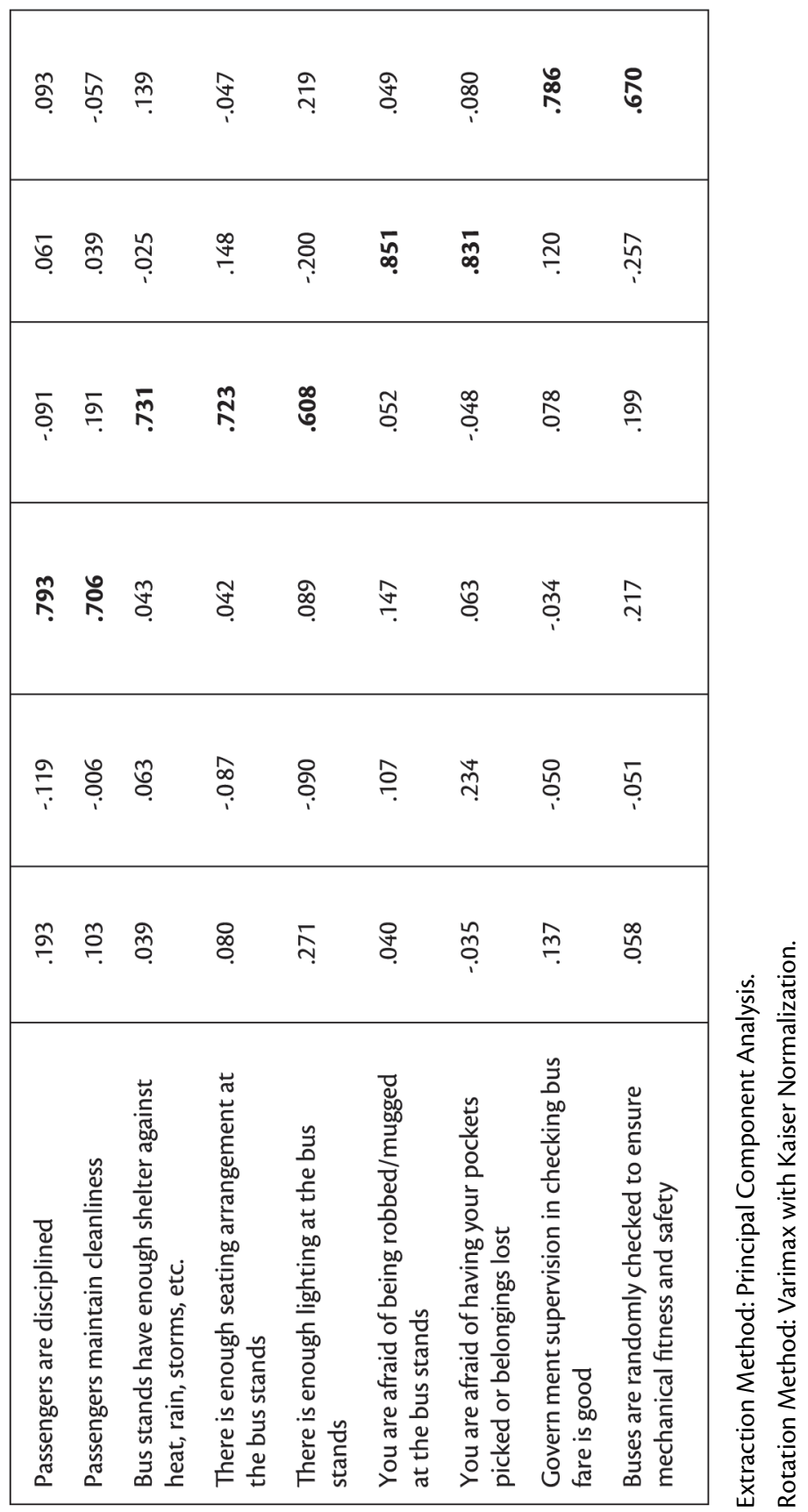


Table 2. Descriptive Statistics

\begin{tabular}{|l|c|c|c|}
\hline & Mean & Std. Deviation & $\boldsymbol{N}$ \\
\hline Satisfaction & 2.95 & 1.49 & 248 \\
Change several buses & 3.95 & 2.30 & 248 \\
to reach destination & & & \\
Staff behavior & 3.38 & 1.86 & 248 \\
Comfort & 2.74 & 1.22 & 248 \\
Ride quality & 4.96 & 1.39 & 248 \\
Copassengers & 3.91 & 1.45 & 248 \\
Bus stand facilities & 1.80 & .98 & 248 \\
Insecurity perceptions & 5.39 & 1.60 & 248 \\
Supervision & 2.65 & 1.60 & 248 \\
\hline
\end{tabular}

improvements in each of these dimensions to bring about a satisfying and valuedriven bus service system in Dhaka City.

The final factors derived from factor analysis, along with the two single-tem measures, were used as independent variables in a multiple regression model to test the hypotheses and determine their ability to explain and predict passenger satisfaction.

\section{Results and Recommendations}

This study suggests that several variables have major implications for delivering satisfaction to bus passengers and for shaping travel behaviors that can lead to a more systematic and efficient traffic system in a city that is beleaguered by its population pressures and unimaginable traffic tangle. The final regression model had an overall $\mathrm{F}_{6,238}$ value of $22.54(\mathrm{p}<.001)$ with an $R^{2}$ of .349 and adjusted $R^{2}$ of .327. Considering that no prior scales and measures were available for this particular research, the results explaining 34.9 percent of the variation in the dependent variable were very encouraging.

Four of the factors-comfort, need to change buses, behaviors of the staff, and government supervision-were found to be significant at the 1 percent significance level $(\alpha)$. A fifth factor, quality of bus stand facilities, was found to be marginally significant with the probability of making a Type I error 10 percent of the time. The three remaining factors-quality of the ride (driving practices), 
copassenger behavior, and feelings of insecurity-were not found to be significant in predicting passenger satisfaction.

Table 3 summarizes the regression results of the final model. The standardized beta $(\beta)$ values indicate that the factor "comfort" had the greatest impact on passenger satisfaction. Apparently, the comfort level provided by the city's buses is a major element that leaves much to be desired, attenuating perceived value and satisfaction.

With the exception of some premier buses that ply a limited number of key city routes, owners/operators of a large proportion of the buses, including government-owned Bangladesh Road Transport Corporation (BRTC) buses, do not pay adequate attention to passenger comfort. Internal facilities, such as lights and fans, are frequently out of order or in need of repair. Many of these buses do not have fans and lights at all. Other amenities, such as lighting during night travel and better airflow and ventilation, must also be constantly monitored to ensure a desirable passenger experience. Basic passenger requirements, like comfortable seats and open windows for airflow, also do not measure up to standards. Many public buses are minibuses, which do not provide adequate legroom or even adequate ceiling height for standing. Passenger discomfort increases during rush-hour traffic when riders have to travel standing all the way in extremely crowded conditions. The results suggest that if comfort can be increased, passenger satisfaction can also be increased significantly, leading perhaps to greater proclivity to use public buses. Comfort is a huge passenger priority and basic standards for comfort must be established and monitored to ensure that the city buses adhere to them.

Staff behavior had the second most impact. Staff managing the embarkation and disembarkation of passengers and collecting fares often lack civility as indicated during the in depth interviews. However, it is important to add that the type and nature of the passengers sometimes necessitate such behaviors, especially when they try to avoid paying for the service. While rude behavior of the staff is not displayed with every passenger, it appears to affect those who use bus services. Many people would like the staff to improve their behavior with all passengers if customer satisfaction is to be improved.

To minimize adverse behavior, a complaint system may be installed to track offenders and take effective action against them. This means installing a mechanism through which the particular bus and the particular employee can be identified via color coding and name tags with visible identification properties. Consideration may also be given to training and certifying transportation workers 


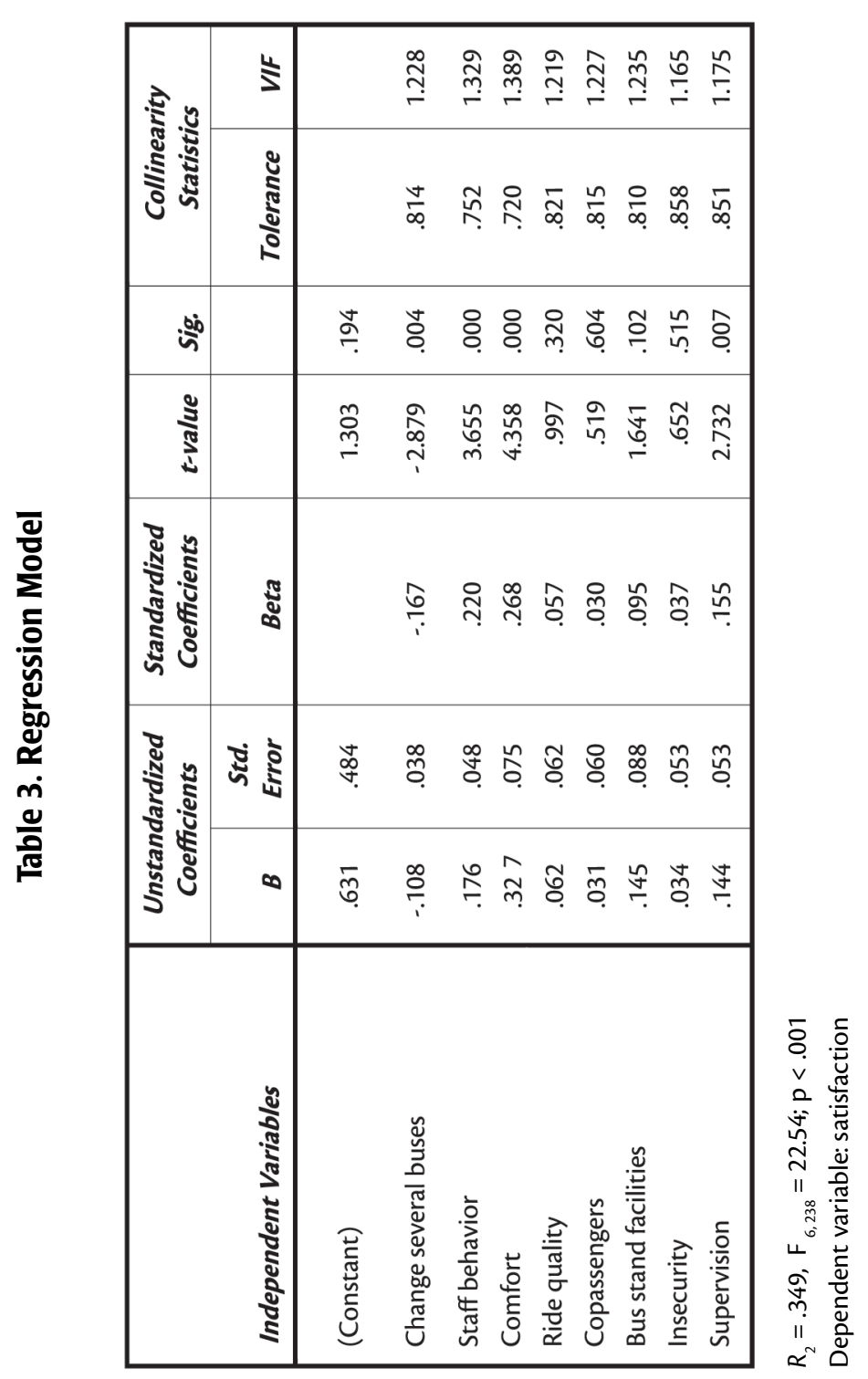


placed in the service of the general public. Such training and certification are actually needed across the board in all service sectors and may even be introduced in school curriculums to sensitize young citizens to the needs of society.

If capacity restrictions (i.e., the number of passengers on a bus) can be imposed via better supervision (after many more buses are introduced in the city system), and if ticket prices can be collected before people board buses, perhaps the staff would behave less rudely. By changing the processes, customers would not have to interact as much with the staff or endure their bad behavior, thereby improving their satisfaction with bus services.

Passengers also indicated that changing buses several times to reach their destinations heightens their dissatisfaction. As the city's population continues to grow, ways must be found to provide more direct services to different customer segments via proper routing, scheduling, color coding of buses, and adjusting capacities for different routes (minibuses, regular buses, maxibuses, etc.), depending on the demand.

Perceived government supervision of the buses emerged as the next dimension influencing passenger satisfaction. Many of the public buses are very old and susceptible to mechanical failures. These buses, including the government-owned BRTC buses, are also unfit for road use because of their battered appearances and the dark black smoke they emit. Their exteriors are often severely damaged, and vital accessories like back lights, side lights, indicator lights, and wipers are either missing, broken, or nonfunctioning. Such confidence-diminishing features are easily visible to the passengers. If similar problems exist in the internal/mechanical components of the buses like the engine, carburetors, radiators, clutches, spark plugs, master cylinders and so on, they pose threats to passenger safety. As a result, people may have serious reservations about traveling on these buses. In fact, a stalled bus in the middle of the road is a common sight in Dhaka City, adding to passenger inconvenience and the already chaotic conditions on the streets. This finding calls for better supervision of innercity buses.

When supervision is visible and vigorous, it is likely to instill greater confidence in the passengers that there will not be any price gouging and that the mechanical fitness of the buses would be ensured so that they would reach their destinations safely and on time. Clearly, the need for visible and vigorous enforcement of price and mechanical fitness are important elements for bus passenger satisfaction. 
Finally, inadequate facilities at bus stands were identified by our model as another source of dissatisfaction among passengers. These facilities are quite deplorable, exposing commuters to crime, discomfort, uncertainty as to whether the buses would stop, and many other physical and psychological costs that substantially exceed the benefits of bus travel. Many bus stands do not offer protection from the sun, rain, dust, pollution, and other elements that have significant implications for health or safety. Often, passengers are seen waiting on sidewalks for buses while blocking the paths of pedestrians. These passengers have no place to sit. Sometimes the bus stands are situated near dumpsters, creating an unhealthy and suffocating situation for passengers. Unless these situations are remedied, expecting people to use a more efficient mode-adopted widely in developed and many developing countries-will not materialize. The consequences are dire: the city's streets will continue to clog up, and this situation will be exacerbated in the future as the city's population continues to grow. The opportunity costs of the traffic tangle are incalculable.

\section{Discussion}

Evidence from travel behavior models suggests that several factors can effectively predict travel demand and mode choice. Among these, fare, frequency of service, waiting time, and travel time have been easy to quantify and integrate into choice models (Ben-Akiva and Morikawa 1990; Koppelman and Wen 1998). Yet additional factors such as service, value, comfort, and psychological and social costs can also influence travel behavior and have not been adequately explored, nor have their relationships to travel satisfaction adequately been investigated. The literature on customer satisfaction and repurchase intentions also demonstrates the role of service quality and perceived value as critical in influencing satisfaction and choice (Teas and Aggarwal 1997; Cronin et al. 2000).

Insights from these studies suggest that people's choice of a transportation mode (city bus service in this instance) would be influenced by the value received from one mode relative to the value received from alternative modes. The proliferation of rickshaws in the city, in this regard, is a crushing indictment of the quality of bus transportation service available to the public. Not only are bus services poor, but also access to them in terms of capacity is deplorable, making the use of rickshaws almost a necessity. If Dhaka City's population is to be made mobile more effectively, both these issues need to be addressed. 
The multipronged strategies that ought to be implemented to bring about changes in transport capacity and usage behavior in Dhaka City must be integrated. For example, increasing the number of buses is absolutely essential, and can be attained via privatization and provision of tax benefits and loans to private parties on easier terms. Supervision can be increased by hiring the city's unemployed but educated youth, who can also be empowered to impose fines on bus operators that do not abide by established standards. A part of the fines collected could be used to remunerate these incentive-driven youth to bring order to the transportation system. Comfort levels must be defined and standards established to ensure appropriate services. Realistically, it may not be possible to offer the standards that exist in the developed countries initially, but they must be gradually upgraded as bus travel begins to play a much bigger role in transporting more people. Bus stand facilities must also be markedly improved. Effective designs could be solicited from schools of architecture via design contests. These designs could then be given to corporate bodies to build according to specifications. Corporate involvement and investment could be induced by allowing companies to market their products in these facilities, rent out the space, or by giving them tax breaks.

Broader measures are also needed to better utilize the limited road capacity to service the transportation needs of the teeming population. It is important, for example, to impose high taxes on existing private motor vehicles to introduce a "large disincentive" for inefficient and frivolous use of precious road space. In particular, tax rates should be increased exponentially for those who own multiple cars but have few users. Private car users must also be charged a congestion fee for driving in key areas of the city (as has been done in central London where the cost is about eight pounds for each trip to the area).

In addition, an "irresponsibility tax" must be levied on those who have built edifices on Dhaka City's streets without making any allowance for parking and expansion of road capacity. Businesses may also be required to pay a surcharge to help build multistoried parking lots in the more congested areas to free up road space. The government should participate in congestion removal by allocating funds to buy nonmotorized vehicles and offering loans to their owners to support other gainful pursuits.

If the city dwellers want better transportation services, they must collectively bear the costs of congestion removal and introduction of rapid mass transit systems such as buses. By paying more to improve the traffic situation, the enhanced efficiencies from time saved may more than compensate for the higher costs they are 
being asked to incur. If this surcharge can be collected in a special account, the work of improving traffic flows, introducing better transportation modes, increasing road capacity, and rehabilitating the displaced workers from the nonmotorized sector can begin almost immediately.

Greater use of bus services can also be promoted through social learning as more social elites use this service, inducing others to emulate them. For example, requiring new and junior-level government officials to use public buses by helping them purchase monthly bus passes at subsidized rates could be a start. Gradually, more senior officials may also be required to do so as they are weaned from their private cars, because in addition to relieving congestion, improper use of their cars can also be reduced. The weaning process may be accelerated by requiring officials to pay for their own gasoline at the beginning and then having them pay for the car in installments. Of course, commensurately, their pay packages must be increased to give them the choice of how they want to use the additional pay. Radical as the idea may be, even public officials of high rank (including cabinet ministers) may be required to use a bus at least periodically to demonstrate their commitment to bringing about positive change. As a consequence, people working in the private sector may also begin to use buses. For this to work, however, the system must offer a service level that is improved quite dramatically from its present state.

This article proposes an outline of what needs to be done to improve Dhaka City's bus services. Key elements are delineated that need to be judiciously addressed. Since this study is the first of its kind based on the passenger's perspective, additional research would be useful in refining the measures and corroborating the model. When such studies confirm, support, and strengthen the findings of this research and offer additional strategic guidance, the state of the public bus transportation systems, not only in Dhaka City but also in other major metropolitan cities that resemble the trying conditions of this megacity, could be significantly improved.

\section{Acknowledgements}

The authors acknowledge the support of the Centre for Research on Business, Economics, and Technology (CERBET) at East West University, Bangladesh, in facilitating the gathering and processing of data. The role of the American Institute for Bangladesh Studies (AIBS) is also recognized for funding a research methodology workshop in 2003 that led to the design and implementation of this study. 


\section{References}

Ali, M. M. 2004. An integrated approach to transportation in the built environment. The Executive Times (July): 32-35.

Andaleeb, S. S. 2003. Traffic mess: Another failure of governance. The Daily Star (November 15).

Asian Development Bank. 2001. Urban transport and environment study ADB TA 3297-BAN. Final Report. Prepared by Intercontinental Consultants and Technocrats Pvt. Ltd.

Banglapedia $($ Asiatic Society of Bangladesh, road transport section.

Ben-Akiva, M., and T. Morikawa. 1990. Estimation of switching models from revealed preferences and stated intentions. Transportation Research 24A: 485-495.

Button, K. J. 1993. Transport economics, 2nd ed. Edward Elgar Publishing Limited.

Ciuffini, F. M. 1995. Transport and public spaces: The connectivity tissue of the sustainable city. The Sustainable city: A European Tetralogy. Dublin: European Foundation for the Improvement of Living and Working Conditions,

Cronin, J. J., Jr., M. K. Brady, and G. T. M. Hult. 2000. Assessing the effects of quality, value, and customer satisfaction on consumer behavioral intentions in service environments. Journal of Retailing 76 (2): 193-218.

Department of Environment, Transport and the Regions. 2000. Transport 2010: The ten-year plan for transport, London: DETR, The Stationery Office.

Disney, J. 1998. Competing through quality in transport services. Managing Service Quality 8 (2): 112-118.

Edvardsson, B. 1998. Causes of customer dissatisfaction-Studies of public transport by the critical-incident method. Managing Service Quality 8 (3): 189-197.

Ghani, O. 2003. Haphazard bus stopovers cause gridlock. New Age, Metro, Dhaka (August 15).

Ison S., and S. Wall. 2002. Attitudes to traffic related issues in urban areas of the UK and the role of workplace parking changes. Journal of Transport Geography 10 (1): 21-28. 
Jen, W., and K. Hu. 2003. Application of perceived value model to identify factors affecting passengers' repurchase intentions on city bus: A case of Taipei metropolitan area. Transportation 30: 307-327.

Karim, M. M. 1998. Light rail transit in Dhaka. The Daily Star: Features, 2, 11 (August 23).

Koppelman, F. S., and Wen C. H. 1998. Alternative nested logit models: Structure, properties, and estimation. Transportation Research 32B (5): 289-298.

Macario, R. 2001. Upgrading quality in urban mobility systems. Managing Service Quality 11 (2, 4/5, 6): S747-S753.

Mannan, M. Shafiqul, and M. M. Karim. 2001. Current state of the mobility of the urban dwellers in greater Dhaka. Paper (No. 173) presented at the 94th Annual Conference and Exhibition of Air and Waste Management Association. June 24-28. Orlando, FL.

Mishra, R. K., and R. Nandagopal. 1993. State transport undertakings in India: Reforms and privatization strategies. International Journal of Public Sector Management 6 (5): 42-55.

Morris, M., S. Ison, and M. Enoch. 2005. The role of UK local authorities in promoting the bus. Journal of Public Transportation 8 (5): 25-40.

Nunnally, J. C. 1978. Psychometric theory, 2nd ed. New York: McGraw-Hill.

Pucher, J., H. Park, and M. H. Kim. 2005. Public transportation reforms in Seoul: Innovations motivated by funding crisis. Journal of Public Transportation 8 (5): 41-62.

Teas, R.K., and S. Agarwal. 1997. Quality cues and perceptions of value: An examination of the mediation effects of quality and sacrifice perceptions. lowa State University Working Paper 37, 6.

World Bank. 1999. World bank to finance projects to help solve Dhaka's traffic and air Pollution woes. News Release No. 99/2074/SAS.

\section{About the Authors}

Syed SAAD ANDAleeb (ssa4@psu.edu) is professor and program chair of marketing at the Sam and Irene Black School of Business, Penn State Erie. He is also the editor of the Journal of Bangladesh Studies. Dr. Andaleeb has a Ph.D. from the 
University of Illinois at Urbana-Champaign, has published widely, and conducts research on the service sector in developing countries including health, transportation, and banking. He is presently involved with capacity development at the institutions of higher education in Bangladesh for which he has been supported as a Senior Fulbright Scholar and twice as a Fulbright Senior Specialist.

MAHMUdUl HAQ (mhaq@bracuniversity.ac.bd) is assistant professor in the Department of Management and Business, BRAC University (Bangladesh). He obtained his bachelor's and master's degrees from the Department of Management, Dhaka University, and has an MBA in finance from the University of Memphis. He has taught at Independent University (Bangladesh) as a lecturer and senior lecturer. Mr. Haq has published in several national and international journals.

RUBINA I. AHMED (rubinaiahmed@yahoo.com) completed her MBA from Southern Illinois University in 2005 under a Fulbright scholarship. She also holds an MBA in international business from Maastricht School of Management (the Netherlands) and from the Independent University (Bangladesh) joint MBA program. She was a senior lecturer in the Department of Business Administration at East West University (Bangladesh) from 2001 to 2006. Before joining academia, she was the human resource coordinator in a nongovernment microcredit institution in Bangladesh. 